\title{
Open innovation and the evaluation of internet-enabled public services in smart cities
}

DOI:

10.1016/j.technovation.2018.07.003

\section{Document Version}

Accepted author manuscript

Link to publication record in Manchester Research Explorer

\section{Citation for published version (APA):}

Paskaleva, K., \& Cooper, I. (2018). Open innovation and the evaluation of internet-enabled public services in smart cities. Technovation, Technovation(December), 4-14 . https://doi.org/10.1016/j.technovation.2018.07.003

\section{Published in:}

Technovation

\section{Citing this paper}

Please note that where the full-text provided on Manchester Research Explorer is the Author Accepted Manuscript or Proof version this may differ from the final Published version. If citing, it is advised that you check and use the publisher's definitive version.

\section{General rights}

Copyright and moral rights for the publications made accessible in the Research Explorer are retained by the authors and/or other copyright owners and it is a condition of accessing publications that users recognise and abide by the legal requirements associated with these rights.

\section{Takedown policy}

If you believe that this document breaches copyright please refer to the University of Manchester's Takedown Procedures [http://man.ac.uk/04Y6Bo] or contact uml.scholarlycommunications@manchester.ac.uk providing relevant details, so we can investigate your claim.

\section{OPEN ACCESS}




\title{
Open innovation and the evaluation of internet-enabled public services in smart cities
}

\author{
Krassimira Paskaleva (Corresponding author) \\ ${ }^{1}$ Manchester Institute of Innovation Research, Alliance Manchester Business School, \\ The University of Manchester, United Kingdom, k..paskaleva@manchester.ac.uk \\ Ian Cooper \\ ${ }^{2}$ Eclipse Research Consultants, Cambridge, United Kingdom, \\ ian.cooper@eclipseresearch.co.uk
}

\begin{abstract}
This article is focused on public service innovation from an innovation management perspective. It presents research experience gained from a European project for managing social and technological innovation in the production and evaluation of citizen-centered internet-enabled services in the public sector. It is based on six urban pilot initiatives, which sought to operationalise a new approach to co-producing and co-evaluating civic services in smart cities - commonly referred to as open innovation for smart city services. Research suggests that the evidence base underpinning this approach is not sufficiently robust to support claims being made about its effectiveness. Instead evaluation research of citizen-centred internet-enabled urban services is in its infancy and there are no tested methods or tools in the literature for supporting this approach. The paper reports on the development and trialling of a novel Co-evaluation Framework, indicators and reporting categories, used to support the co-production of smart city services in an EU-funded project. Our point of departure is that innovation of services is a sub-set of innovation management that requires effective integration of technological with social innovation, supported by the right skills and capacities. The main skills sets needed for effective co-evaluation of open innovation services are the integration of stakeholder management with evaluation capacities.
\end{abstract}

\section{Highlights}

- Public sector service development should be treated as a distinct subset of innovation management.

- Co-production and co-evaluation of smart city services are parallel, interactive processes.

- Evaluation of smart city services requires effective integration of technological and social innovation.

- Living labs require stakeholder engagement throughout the entire life cycle of services development.

- Managers need skills to integrate stakeholder management effectively with coevaluation. 


\title{
Keywords
}

\author{
Co-evaluation \\ Co-production \\ Smart city services \\ Open innovation \\ Innovation management \\ Stakeholder management
}

\section{Introduction}

Due to fiscal pressures, technological progress and globalisation, there has been an increasing demand on governments to reform public services to improve service effectiveness, quality and utilisation (Kettl, 2005; Osborne and Brown, 2013). This has spotlighted government performance and heightened citizens' expectations (Fredrickson and Smith, 2012). In response to this push for performance improvement, some local governments have begun to pay attention to and to track more regularly citizens' evaluations of government (Van Ryzin and Innerwahr, 2007). As a result, public managers at the local level are now facing an expanded portfolio of public service responsibilities, including assessing their own effectiveness (Dollery et al., 2010). The delivery of better services to citizens has thus required both recognizing the pressures for innovation and quality in government and the need for capacity building in public administration (Rondinelli, 2013). According to recent studies on public sector services, the most under-used road to innovation is through asking "customers" not just to assess how services are delivered, but also to help to (co)produce them (Jaeger, 2013). And while research on and practical attention to the co-production of public services is increasing, systematic and comprehensive attention to evaluation is still not evident (Durose et al., 2014). This is surprising since many proponents highlight its potential for changing traditional, government-centric approaches to delivering and managing public services (Osborne et al., 2014). There is much to learn from drawing attention to the experiences in public service evaluation in different sectors and localities (Percy, 1984). Given that co-production involves the active and productive involvement of the citizens in service development (Paskaleva et al., 2014), traditional approaches to the evaluation of public services no longer appear suitable. Yet, as illustrated below, involving citizens in co-productionas a collaborative process of service development - and in co-evaluation - as an open innovation assessment method - is far from easy. In practice, public managers may not have all of the skills they need to do this effectively. The gap and puzzle here is that theoreticians - and those responding to them in the public sector - don't appear to need to test theoretically based claims before proclaiming them.

Despite the challenges, in the quest for providing better public services, many cities around the world have been increasingly looking towards open innovation approaches and new technologies to produce "smart city" services. In Europe, more than 220 smart city pilot projects have been developed throughout the late Framework 7 (2008-2013) of the European Union and the current Horizon 2020 Programme for research and innovation. These are meant, by definition, to be citizen-centric. In "smart cities", where Information and Communication Technologies (ICT) are used to 
enhance quality of life of citizens - government partners are expected to actively listen to the needs of citizens, as service users are deeply involved in development processes. Co-producing services with users and stakeholders is heralded as leading to more effective and innovative public services which will provide greater levels of citizen and community satisfaction. Citizen-engagement and Living Labs (LLs) in particular have been boosted as the new ways to speed up the innovation capacity of public agencies and other organisations in co-producing smart city services (Paskaleva et al., 2014; Ståhlbröst and Holst, 2012). The smart city paradigm, which arose since the mid-1990s, has been around long enough for the validity of its basic precepts, principles and claims to have been established through empirical study. This has not happened.

The open innovation record of the public sector remains weak and there is a strong deficit of analysis of service innovation through co-production (Osborne et al., 2014). Existing evidence is not sufficiently robust to support claims being made for its effectiveness (Strokosch, 2013). Evaluation research of citizen-centered internetenabled urban services is also in its infancy. There are no tested methods or tools in the literature for effectively supporting co-production and co-evaluation - as an inclusive assessment method. Nor have the associated skills and capacities of the public service managers in producing services in the wider context of open innovation been explored. This study responds to these limitations by proposing a new coevaluation framework and method to gauge the success of co-producing smart city services. The purpose of the paper is to generate new theoretical insights and to test theory-based claims currently used to promote LLs.

A case study method is used in six European city pilots to examine how coevaluation can be introduced to run in parallel with co-production in an effort to move beyond post-evaluation to more inclusive processes where the public have a direct participation in both the development and assessment of services. Leading edge literature on open innovation and public service evaluation is first reviewed against assessment of service evaluation in LLs, examined in the context of co-production of services in smart cities. Key factors affecting the development of successful public services through co-production are identified. These formed a new co-evaluation framework - placing evaluation in the center of smart city services - that charts the full lifecycle of service co-production. Six pilot initiatives in four cities - Ghent (Belgium'), Bologna (Italy), Cologne (Germany) and Manchester (UK) - trialled the model. In each case public sector staff involved citizens, representing a variety of urban stakeholders. Co-evaluation was made through trialling a process-based selfassessment Toolkit. Based on a review of the cities' own assessment reports, the paper then goes to examine how co-evaluation can be introduced to run in parallel with process of co-production. Analysis of these results is used to inform the specification of the skills and capacities needed by public managers to integrating coproduction and co-evaluation effectively. The paper concludes with a discussion of the implications of this integration for innovation management of public services and future research.

\section{Theory}

\subsection{Innovation of public services}

Although innovation has become central to many government's programmes aimed at improving public services (Albury, 2005; OECD, 2011), there is little evidence yet on 
how innovation is managed in public service organizations (Bommert, 2010), especially in regard to the service economy as an expression of customer-oriented and citizen-centered, value-enhancing offerings (Gummesson, 1994). Literature on service innovation has already identified open innovation as one of the most promising new approaches that have challenged not only service research (Vargo et al., 2008) but public service innovation as well (Boyle and Harris, 2012; Osborne et al., 2014). Ten years after he first coined the term "open innovation" in 2003, in his latest book Open Service Innovation, Chesbrough (2011) defined open innovation as the new paradigm for management in the $21^{\text {st }}$ century. Here co-creation with customers enables sustainable business models that drive continuous value creation for users. And, although open innovation has been widely used in the private sector, many researchers have pointed to similarities and differences between private and public sector innovation. According to Bommert (2010) and Hilgers and Uhl (2010), while innovation in the private sector tends to focus on novel product development and gaining competitive advantage, innovation in the public sector is usually driven to improve service performance and add value in terms of public benefit. Like private firms, the innovative ideas and solutions to the problems of cities, for example, can be provided both internally and externally through cooperation with the government and its citizens. But since innovation is a highly iterative and complex process, in which project management is of particular importance to the management of innovation, together with teamworking, piloting and experiments (JISC, 2009), research indicates that there is a growing need to enhancing public sector organizations' capacity for innovation (Borins, 2001) and its management (Damanpour and Schneider, 2009). For this to happen, however, as in the case of e-government evolution, local governments need to learn how to become more responsive to external constituencies (Jun and Weare, 2010) and how to manage collaborative processes. Since its onset, open innovation has become of the most discussed themes within the innovation management literature (Huizingh, 2011; Santos, 2015). Yet, comprehensive records of service innovation through co-production are hard to find and existing knowledge about the necessary innovation processes, their efficiency, and the results they achieve is fragmented (Strokosch, 2013). There is also a limited knowledge and awareness of the full range of tools available to managers for accelerating innovation (OECD, 2012: Osborne et al., 2014).

\subsection{Evaluation of public services}

As early as mid-1990s Sanderson (1996) underlined the role of evaluation in promoting social learning as the basis for achieving effective public services. Gümmersson (1994) also argued that service management should not just be treated in specific service management terms but also in broader, societal terms, from both, practitioner and research viewpoints. Seen from this perspective, service management concerns not only service organizations, but also constitute a social paradigm. As Pestoff later argued (2006), the new service economy is an expression of customer and citizen-oriented, value-enhancing offering, where there are obvious benefits of customer co-creation of value in the services. This puts management of public services squarely in the realm of open innovation. Yet, open innovation evaluation of public sector services is still to be examined.

Much more needs to be learnt about how open innovation contributes to knowledge about public service management._A recent Research Policy special issue on Open Innovation (Joel et all. (Eds.), 2014) revealed that two of the three new 
trends in open innovation research are better measurement and linking that research to the management literature. Earlier, Mulgan and Albur (2003) reported that transparent measurement systems for assessing the success or otherwise of innovations are vital to robust analysis and creating cultures of learning for studying service innovation in the public sector. The main areas in which appropriate and specific measures need to be set include improvements in relevant outcomes, service responsiveness to needs of individuals and localities, and peer and user involvement - including the formation of real time learning communities around specific innovations" (p.14). Here increasing user participation in public services poses particular challenges for evaluation. Rigidly-fixed pilots and programmes may inhibit innovation. Rather than formal evaluation that is based on fixed models, it may be more useful for projects to adapt, learn and innovate in real time (Ibid). For this, however, appropriate processes, mechanisms and activities need to be put in place in order to analyse, evaluate and learn about the process of innovation.

\subsection{Open innovation of municipal services through co-production}

With the growth of the service economy, there has been a radical re-interpretation of service delivery in the public domain. Municipal services are no longer simply being delivered by professionals in public agencies but are being co-produced by users and their communities. Accordingly, conceptual frameworks for public services have moved to user and community co-production approaches (Pestoff, 2012). A new model of public service provision - known as "co-production" - has emerged, generally characterized by the involvement of service users and members of the community in the provision of public services (Paskaleva et al., 2016). Propositions are made that relate citizen co-production to outcomes such as responsiveness, effectiveness, and efficiency (Pestoff, 2012). But this new drive towards coproduction has also demanded revision of traditional conceptions of public service management in order to account for co-production as an integrating mechanism between the public sector and citizens - claimed to lead to a better use of each other's resources, assets, and contributions so that better outcomes or improved efficiency are achieved (Bovaird and Loeffler, 2012).

Others have argued that co-production can only produce results if it is backed up by practical testing of techniques to show it is resulting in positive change. But in the absence of such testing, the potential of co-production can be seen as greatly underestimated (Bovaird, 2007; Meijerm, 2012). In this sense, co-production raises important issues about the capacity of public organisations and other stakeholders to co-produce the wished-for services effectively (Osborne et al., 2014). Co-production can have wide effects on service innovation, affecting both the demand and quality of the services (Chen et al., 2011). Whether these effects are positive, however, strongly depends on the expertise and commitment of the involved partners (Pestoff, 2012). Raising the ability of service organisations to manage co-production means strengthening their open innovation capacity.

Seen from a normative perspective, co-production is being recommended at all stages of the public service cycle - decision, design, production, and (eventually) evaluation (Cahn and Gray, 2012; Pollitt et al., 2007). Yet more empirical studies of co-production are being asked for to show how this can be achieved in practice. In urban municipalities specifically - where the cycle of public services development is seldom covered by one single organization and citizens present sophisticated demands for the nature and quality of services - special attention must be paid, as Cecilia et al. 
(2015) emphasised, to how co-production can be managed effectively in what are undeniably complex multi-actor and multi-level settings. This stresses the need for service managers to acquire new roles, employ new management methods, and deploy skills that ensure decisions regarding public services are shared between all actors entwined both vertically and horizontally through a collaborative approach at all stages of development. Therefore, to ensure that citizens' concerns and wishes are taken into account, public sector organizations must open the "black box" of development and also look at output and outcome levels as Pollitt et al claimed (2007). These points suggest that there is a need for a radical shift to service coconcept, co-decision, co-design, co-development, and co-delivery based on collaboration between a wide range of actors seeking to produce services that are beneficial for all stakeholders. This also means that in order to ensure that coproduction works in practice, co-producers need to be involved in evaluation (Bovaird Loeffler, 2012). Yet, as Loffler et al. (2008) have found, there is little evidence that users or other stakeholders are being encouraged or trained to take part in the evaluation of services. In the current study, we contribute to the ideas emerging from recent collections of works on service co-production by adding co-evaluation as critical to the management of open innovation in public services. The paper also responds to the call to advance research in service management by engaging in processual theorizing as well as by employing different methodologies, perspectives and approaches (Osborne et al., 2014).

\subsection{Evaluation of smart city services}

ICTs offer significant advances for enabling citizen co-production in government services so making them more viable and effective (Linders, 2012). The debate has particularly flourished as a "smart city" theme. Indeed, for a city to be smart is seen as requiring it to develop and manage a variety of innovative services that engages citizens in co-production via interactive and internet-based applications (Kuk and Janssen, 2011). Smart city research has stated the importance of acknowledging both internal and external stakeholders during the development of public e-services (Flak and Rose, 2005). Such stakeholders include other government authorities, businesses (Holgersson and Karlsson, 2014) and citizens (Lindgren and Jansson, 2013; Lee and Lee, 2014). Knowledge about stakeholder needs and skills is seen as essential for successful co-production of public e-service (Axelsson et al., 2010). And with open innovation of smart city services now advancing, there is a growing need of shifting focus from intra-organisational to inter-organisational challenges in involving the citizens in developing public e-services that better satisfy their needs and wishes.

Smart cities are considered a paradigm of city development and planning which "connects the previously unrelated dimensions of sustainability, green development, digital and smart spaces, innovation and creativity" (Komninos, 2009, p. 335). Placed

at the heart of this perspective on urban change are citizens as co-creators and collaborators: people are seen as a critical creative resource from which "open innovation" can flower in smart cities (Almirall and Wareham, 2008; Paskaleva, 2011). Against this backdrop, the SmartiP project brought together six urban pilots from Europe, based in the public sector, where citizens were taken as a "central force" in the co-production of civic services. This 13-partner initiative, funded under the EU FP7 CIP programme (Cordis, n.d.), was used to explore the role of citizens as cocreators and co-producers in service projects. Evaluating the pilots' attempts at coproduction can begin fill what appears to be a substantial knowledge gap in the 
evaluation of smart city service management. To identify the trends and the challenges posed by seeking to co-evaluate smart cervices, two relevant fields of knowledge are relevant - evaluation of IT systems and LLs evaluations.

Academic literature on IT systems evaluation is broadly unanimous that robust evaluation is an 'Achilles' heel' in both theory and practice. Evaluation is often seen as a "necessary evil" in IT projects, but in spite of its' fundamental importance to both scholars and practitioners, it tends to be neglected or to be an "after thought" (Jones et al., 2007). Cited reasons for absence of evaluation are "problems identifying and quantifying benefits and opportunity costs, unfamiliarity with evaluation techniques, difficulty in interpreting results, and lack of time, data, information or interest" (Grimsley and Meehan, 2007). As a result, the field of IT evaluation has been dominated by concerns about cost-benefit analysis and return on investments, using traditional econometric methods (Irani et al., 2008). Traditional, "mechanistic" evaluations, where they have been done, have tended to incorporate user experience and satisfaction in the final system development phase (Al-Yaseen et al., 2008). A closer look at evaluation approaches adopted in LLs, which sought early citizen involvement in designing and developing IT systems, can provide useful lessons.

Commonly defined as user-centred innovation ecosystems based on businesscitizens-government-academia partnerships (Paskaleva 2011), LLs are widely viewed as effectively enabling users to take part, not just in the research, but also in development and innovation processes in Smart Cities Europe. Using open, collaborative innovation, LLs seek to encompass societal and technological dimensions to develop services that are more personal, optimal, and affordable, allowing (public sector) services providers to find new, more affordable approaches to service creation and personalisation (Paskaleva et al, 2014). But LLs' ability to deliver on this front has been strongly questioned (Mulder and Stappers, 2009). Originally, LLs grew out of a 1999-2000 initiative by Nokia Research Labs, the VTT Finnish national research centre and Helsinki City Council to find new ways of trialling and testing ICT products through user participation. Now there are 400 LLs in the European Network of Living Labs developing collaborative networks to put new smart city ideas into practice in the areas of smart health, smart work and mobility, smart learning, smart energy, and smart business, to name a few. Literature has already identified innovation management as a component of a LL (Ståhlbröst and Holst, 2012). Yet, well documented evaluation of smart city co-production processes, policy_implications and impacts of service innovation in LLs is missing. The continuing rise of open innovation in the public, voluntary and private sectors means this gap urgently needs to be filled.

\subsection{Full lifecycle co-evaluation of co-production in $L L s$}

Searching for best practice in evaluation of LLs in Europe identified 23 cases, each one concerned with separate stages of product development. The FormIT methodology - developed by the Centre for Distance-spanning Technology at Luleå University of Technology, Sweden - considered evaluation at more stages than in other LL approaches; namely decision, solution design, and prototype (Ståhlbröst and Holst, 2012). Although more comprehensive than others, FormIT dos not cover the full life cycle of service development (Irani and Shafir, 2007; Paskaleva et al, 2014) and it does not provide for an inclusive and continuous process of self-assessment, occurring in parallel with co-production of public services. The SmartiP open 
innovation model of service development presented in Figure 1 was constructed to overcome this.

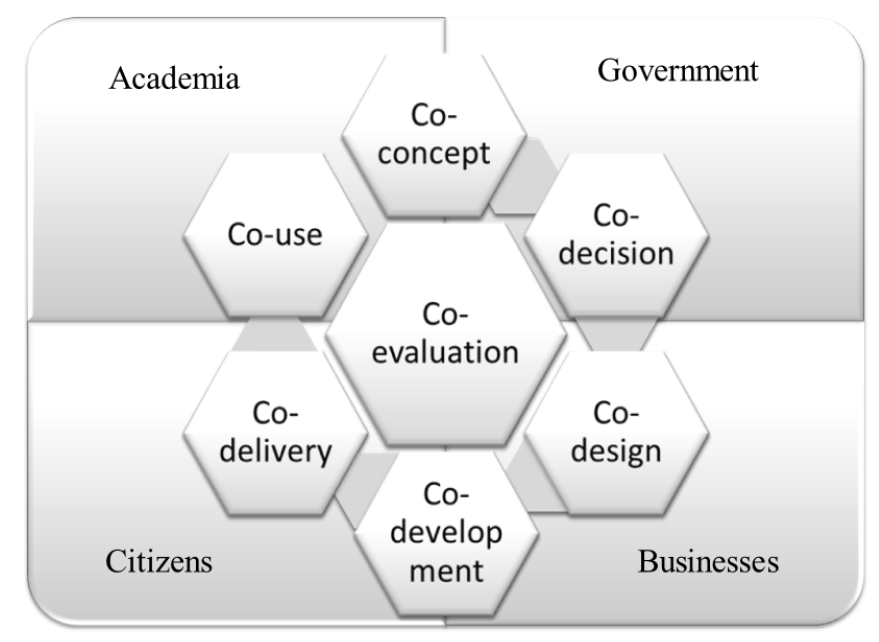

Figure 1. Open innovation model of smart city service development (Based on Paskaleva et al., 2012)

This new model emphasises the central place of co-evaluation in the coproduction of smart city services. It charts the full life cycle of the process - from concept, onto decision-making, design, development, delivery, through to use of the service, with co-evaluation being integral to progress throughout all stages. A key characteristic of the approach is that all four types of stakeholders - government, businesses, citizens and researchers (generally referred to "citizens" in this work) should play an active part in the entire service life period - from need identification to a successful service. Accordingly co-production is also expanded in time so that it encompasses the use and co-use of the service so a continuous enhanced development can be ensured, aligned with the changing citizens' needs and objectives, as well as with replicability and re-use of the service. The proposed co-production model suggests a systematic and continuous approach to structuring evaluation tasks too.

\section{The SmartiP co-evaluation framework}

As a strategically-orientated LL project, SmartiP -"Smart Metropolitan Areas Realised by Smart Citizens" (SmartiP, 2010) was funded by IST CIP Programme of the EU's Seventh Framework to promote the use of open innovation for creating Internet-enabled services in smart cities. Between 2011 and 2014 SmartiP explored how "smart citizens" can be empowered in a 'smart city' environment by broadening the concept of "technology users" to "citizens as co-decision-makers" and by incorporating elements of strategic agenda setting and policy outcomes into the process of co-producing and co-evaluating civic services. The intention was to take experience developed from other existing user-centred, open innovation initiatives in Europe, particularly those developed through LLs, and to apply this to the challenge of transforming public services by empowering 'smart citizens' who would be able to use and co-produce innovative civic services within their emerging smart citizens' collaborative networks. The project's far-reaching objective was to enhance the 
ability of cities to grow and sustain a "smart city" ecosystem which is used as an enabling environment for supporting new service opportunities.

A vision central to SmartiP is that "smart cities" require "smart citizens" if they are to act inclusively, innovatively and sustainably. To achieve this, however, cities need to embrace making their citizens smart, enabling them to have the capacity and confidence to use state-of-the-art internet technologies so they can transform the way they live and work and improve their quality of life. Internet-enabled smart citizens would then be able to collaborate in new and dynamic ways, co-owning the planning and delivering of services, so co-producing services both for themselves and for those that they live with, care for, and work with. In other words, cities would get "smarter" by engaging and enabling their citizens to become "smart" and co-produce the services they need (Paskaleva et al., 2015).

During 2011 and 2012 open internet platforms for co-producing smart city services were created. Six pilot projects, covering thematic areas of "smart engagement", "smart environments", and "smart mobility" were developed Manchester "Tellus green home watch", Manchester "Community Reporters", Manchester "Oxford Road Corridor" Smart Environment, Ghent "Community game SCOGA/ KLIEK", Cologne "Participatory Budgeting", and Bologna "Smart Mobility Considium". Attempts were made by each city to create circumstances where people could be engaged, enthused and empowered through co-production processes.

\subsection{Integrating technological and social innovation}

One of the main development areas for LLs is to foster social innovation with the help of modern ICT by bringing together technology providers, end-users (costumers), researchers and city authorities. But although the LL community has recognised that public services are at a critical juncture requiring future solutions for public services to be sought through co-production methods with user communities, LLs are still being criticised as serving the needs of technology providers above all (Viitanen and Kingston, 2011). SmartiP was pioneering in recognising the need to integrating technological and social innovation in developing smart city services.

Through literary research, SmartiP researchers from iMinds (Ghent, Belgium) mapped out the critical system functions for gauging the technological success of the new SmartiP services, benchmarked against relevant EU policy references (Paskaleva et al., 2012). Interoperability, Standardization, Open data, Interactiveness, Usability, Sustainability, Transferability, and Openness emerged key to technological innovation. These eight dimensions formed the SmartiP's Technology Innovation Framework that was used by the pilots for assessing the success of their smart city services. As part of this framework, for the purpose of co-evaluation, pilots were provided with definitions of these concepts as well as scales and methods for measuring them (Ibid). SmartiP new services were also intended to demonstrate the potential for building the social capital of the smart city. This was achieved by assessing the effects of the new services on creating smarter citizens capable of engaging in service co-production consciously, purposely and on continuous basis,

\subsection{Towards co-evaluation of smart city services}

By bringing together the citizens-centred approach to smart city services and a LL co-production methodology, SmartiP created an assessment strategy which is multi-dimensional, focusing on all key factors - the actors, their actions, the resulting 
outputs and the outcomes - using a co-evaluation process and ensuring that the idea of "smart citizens" is applicable to all aspects of smart city service development, and focused on related policy impacts. An intrinsic integration of operations, both procedurally and strategically, was sought by encouraging citizens to participate in the development of the services from start to end, through a managed set of activities allowing for effective interactions aiming at improving the overall performance of service development A main characteristic of the new approach is that the citizens are engaged in not only the co-creation of the service value but also in assessing it against achieving their own goals. Fostering self-assessment is the defining focus of coevaluation and the heart of its explicit service innovation agenda. In its concerns for issues as ownership, relevance, involvement, improvement, co-evaluation corresponds to other evaluation approaches - participatory, collaborative, stakeholder-involving, and utilization-focused evaluation (Patton, 2005). It distinguishes from these other approaches by offering a new perspective on what kind of value is created in the smart city service, one that is wished for and apparent to the co-producers and by its capacity building imperative for innovation management of public services. Coevaluation is an open innovation self-assessment method which measures the success of co-producing public services. Service value is not the only dimension created in collaboration with the co-producers; benefits for the smart city and the smart citizens are also generated. With this open innovation approach, the focus of evaluation is shifted on the relationships between co-producers and on to on-going service coproduction processes, focused on achieved outcomes and resulting impacts, taking place in real life situations. Assessment of success of smart city services can thus be achieved by evaluating citizens' engagement and input throughout all phases of coproduction, and not just on a bespoke "evaluation validation" phase after each pilot service where users evaluate and provide feedback on the basis of user testing and feedback, as has been the practice in LLs till now. Self-assessment of process at early stage of co-production is critical to effectiveness of co-evaluation of smart city services as it reveals how and why co-production is geared to achieving all stakeholders' intended services and their use.

The new SmartiP Evaluation Framework anticipates that "formative" and "summative" evaluations are carried out collaboratively to gauge the success of service development projects. The aim here is two-fold: i) to apply evaluation during the whole co-production process so actors can improve their performance and ii) to achieve the desired services (the output of the co-production process) and the outcomes (the SmartIP broader policy objectives). For the city service projects, this means that they should seek to assess their successes from establishing the service "founding framework" right through to the final prototype and the policy implications that may result from the new smart city services.

Two main outcomes-advanced internet-enabled services and smarter citizens for smarter cities - were singled out in the project's Description of Work (SmartiP DoW, 2010) as being at the base of its added value. Gauging these two outcomes required clear demonstration - through structured observations of the pilots' co-production processes. Not just project partners but also major stakeholders in each of the pilots needed to be kept continuously aware of these goals. Improvements in smarter citizens and more inclusive smarter cities were the main indicators against which the success of their collaboration in co-producing smart city services were to be judged. Figure 2 below presents the key factors considered in the form of integrated Evaluation Framework. 


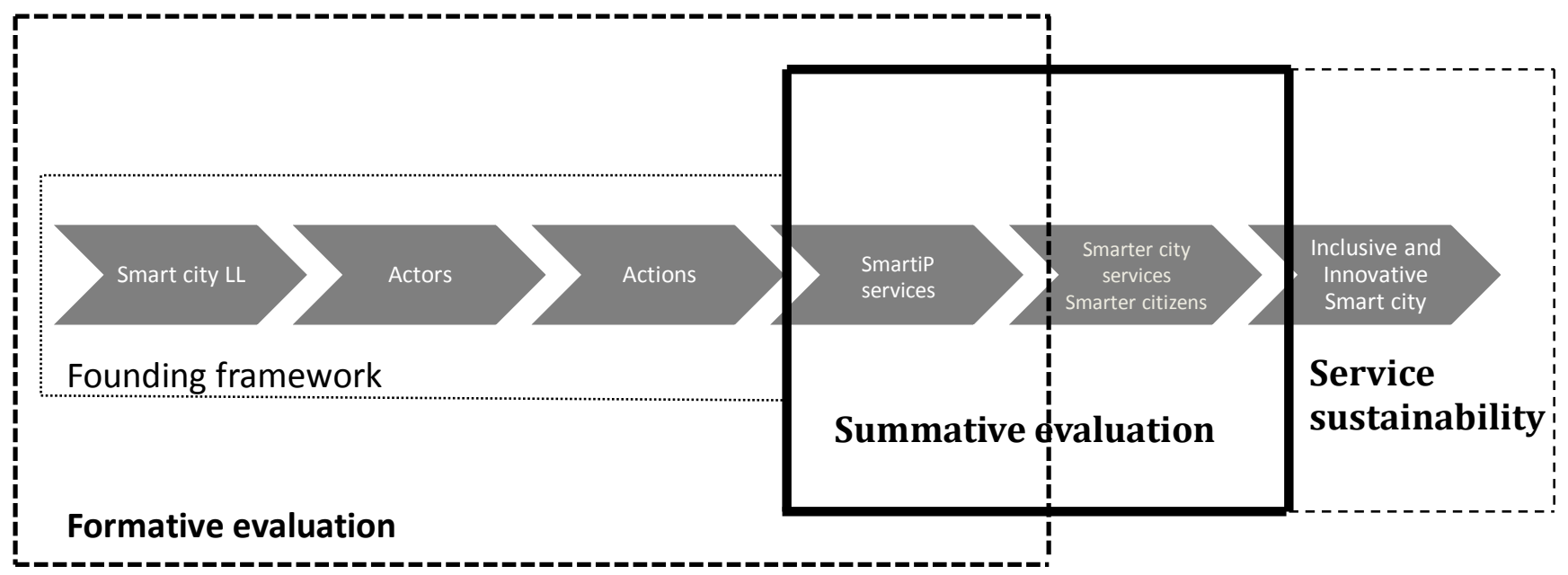

Figure 2. SmartiP integrated evaluation framework

In applying the Framework, both technological and social innovation are evaluated not separately but in their co-relation - assessed against the set of shared objectives and benchmarks established during the full process of co-production and by all stakeholders, in a "real life" open innovation environments (Cooper et al., 2012; Paskaleva et al., 2012). Four types of performance indicators were applied at different stages of co-production: process indicators; output indicators; outcome indicators, and impact indicators. Process indicators were considered most important for assessing performance in the very early stage of co-production, before main production activities progress. Different to existing practices, output indicators were to be employed at intervals, for instance, to gauge the number of stakeholders being engaged or new smart city services emerging. Outcome indicators come into play not just towards the end of the project in order to assess the results of project outputs - but also at the end of every phase of service. Impact indicators are to be applied after the project ends and as consequences of the long term outrun of its processes, outputs and their outcomes could finally be assessed.

\subsection{Building management capacity for co-evaluation}

Open innovation service literature has already shown that project managers lack the necessary expertise to manage collaborative processes successfully (JISC, 2009). Critical to enabling collaboration are the skills and experiences of public sector managers to effectively manage the variety and complexity of the innovation being attempted (Nonaka and Takeuchi, 1995). It is also essential that new service project teams cooperate across organizational boundaries and various disciplines to achieve sustainability goals (Lin and Hsieh, 2010). In smart city LLs, service managers need to employ a step-based stakeholder engagement, including "enlistment", "enrolment", "dialogue" and "participation in innovation networks", with emphasis being placed on the "front end" of the engagement process as a necessary prerequisite of successful services (Paskaleva et al., 2014). Figure 3 below seeks to illustrate what the proceeding discussion highlights as the components required for evaluating coproduction of smart city service. 


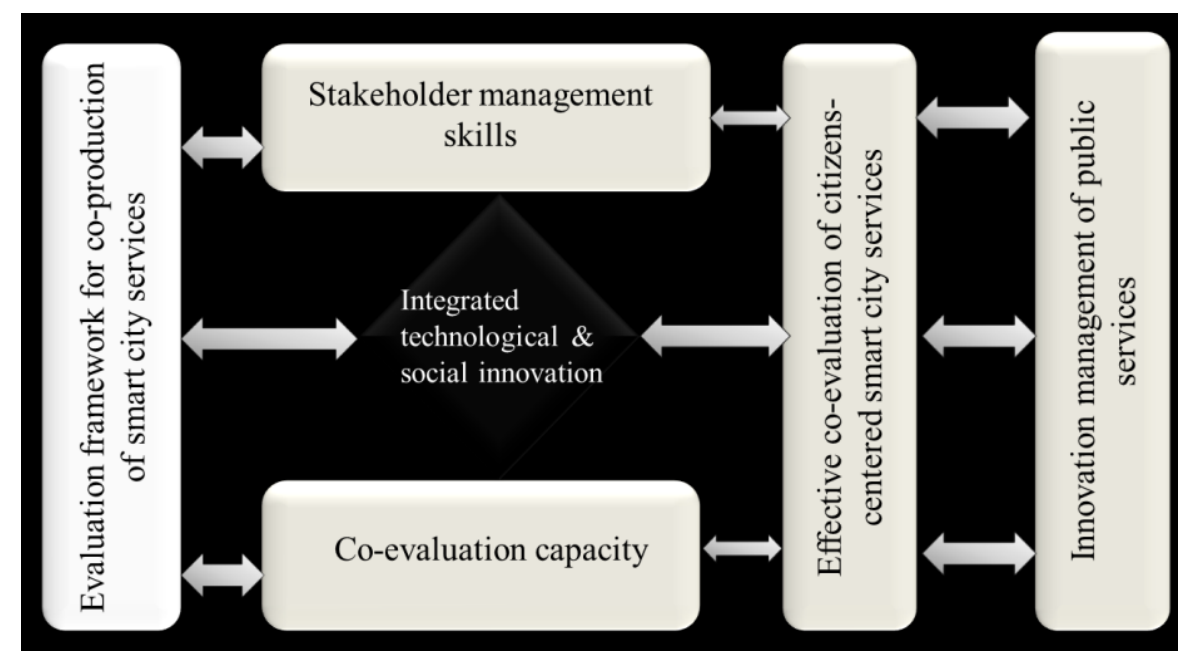

Figure 3. Context of open innovation evaluation of smart city services

As this is shown, project managers require two critical sets of skills to support the co-production of smart city services effectively. First, they need to be able to integrate the technological and social strands involved in innovation in their projects. This integration is shown in the form of a "black box" at the centre of the diagram. The figure further implies that such integration needs to be supported by i) skills in managing stakeholders and ii) by a self (reflexive) capacity amongst stakeholders for evaluating what they are doing.

Figure 4 below is an attempt to unpack the "black box" at the centre of Figure 3. Although highly complicated, Figure 4 is an over-simplification of the range and timing of activities that need to occur to support the integration shown in the black box in Figure 3. Figure 4 is over-simplified because it represents both the production process (shown in the top half of the diagram) and the co-production process (bottom half) as if they were linear. In practice, as parallel evaluation conducted on the EUfunded Peripheria project revealed (Cooper et al 2012; Paskaleva et al 2017), such processes may be highly iterative. They can also involve activities whose timings may seem counter-intuitive to the idealised "progress logic" of the sequencing expressed in SmartiP's Evaluation Framework, see Figure 2 above. 
Figure 4. Simplified integrated co-production process for smart city services (No iterations shown)

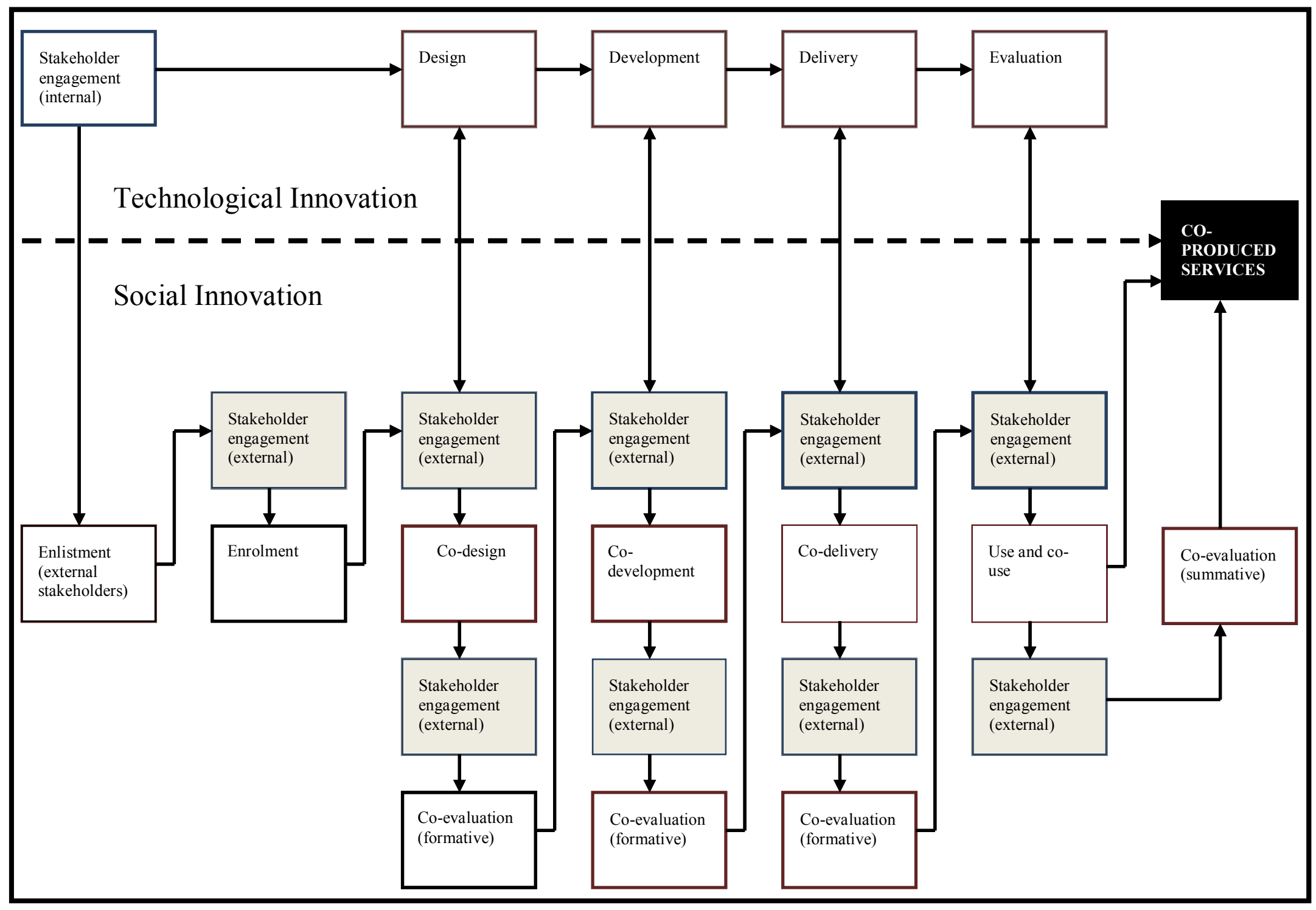


As Figure 4 indicates, project managers need engagement skills to manage internal stakeholders' (project partners) contributions to the production process (top half of diagram). They also need formative evaluation skills to check reflectively on ongoing progress with those internal project partners. Project managers likewise need engagement skills to first enlist and enrol external stakeholders (such as citizens) in the co-production process and then manage their continued contributions (bottom half). They also need the skill of being able to engage those external stakeholders in activities for collaboratively undertaking formative assessments of progress in the coproduction process. In addition, beyond having these management skills to run their technological and social strands separately, project managers also need the skills to ensure that these two processes (in the top and bottom of the diagram) are brought together and integrated effectively throughout the lifetime of their project.

The next sections discuss the extent to which the trial runs conducted of SmartiP's Co-evaluation Framework revealed whether its pilots' project managers possessed the complex mix of skills described above. Analysis is focused on their capacity for co-evaluation and the activities required to support this - in order to conduct self-assessments of progress being made in co-production. Attention is drawn to how acceptable project partners found the kinds of co-evaluation tools and techniques provided for them in the SmartiP Toolkit (See Appendix A).

\section{Methods}

A dual approach was applied in this study. Desk-based research was first carried out to review the literature on public service innovation and evaluation, set against coproduction of smart city services and evaluation in LLs. A wide range of resources were analysed: academic publications, findings from EU projects, strategic EU and state policy documents and programmes, as well as open innovation forums and blogs. The analysis provided a background for i) drawing an integrated Evaluation Framework for Co-production, based on an Open Innovation Model of Smart City Services and ii) conceptualising the context of open innovation evaluation in smart city services using a full lifecycle co-evaluation process. Review of the skills sets necessary for managing co-production successfully enlightened the innovation management perspectives of co-evaluation adopted. The emergent Co-evaluation Framework unveiled the factors that are critical to open innovation evaluation of public services. The development and trial of the SmartiP co-evaluation framework is described below through a series of methodical steps.

SmartiP ran from 01.11.2010 until 31.03.2014. In the first four month of project the research team from the University of Manchester drew up the SmartiP coevaluation strategy, in line with the project's objectives and key EU smart city policy initiatives. The approach was presented to the project team and the European Commission in month 6 at the first Project Review Meeting in Brussels, Belgium. Coevaluation was highly commended by all parties. A draft framework was then developed by the evaluation team. It was introduced to a wide range of project stakeholders in month 10 when most of the pilots were still discussing the nature of their smart services and were thus able to work in co-evaluation on their coproduction process. An evaluation workshop was held in Cologne, Germany in October 2011 with the objective of discussing the SmartiP Co-evaluation Framework and of introducing service actors to key aspects of the self-assessment. A Smart Cities, Smarter Citizens - Co-Evaluation Exercise was conducted with them to both pre-trial the framework and train project managers and other actors carry out the trials 
in their pilots. Twenty five participants from academia, public service management, IT service providers, policy-makers and Living Labs participated in this 1-day workshop. During the morning, presentations were made by the evaluation team on co-evaluation followed by interactive discussions. Principles and process of coevaluation were probed.

The session ended with the key pillars for applying successful co-evaluation in real life situations. This was followed by a $1 / 2$ day 2 -step exercise on self-assessment in which workshop participants, working in city groups, were asked to set up parameters for evaluating their own service success as well as to identify their 'yardsticks' for co-evaluation, including the tools and techniques they wanted to employ and how they proposed to implement them. The results of the workshop were analysed by the project evaluation team and a summary of the lessons learned was sent back to the participants to provide further ideas and feedback. Considering the outcomes of the workshop, and based on the results of the state of the art analyses conducted by the University of Manchester and iMinds, the Manchester team developed a Toolkit for implementing co-evaluation. The Toolkit was approved by all pilot managers and then trialled by them between May 2012 and August 2012. Testing of the Toolkit was carried out in all six pilots through a collaborative process with the service stakeholders. A Guide for preparing, conducting and analysing the results of pilots' trialling of the Toolkit was provided by the evaluation team, each step elaborated in a table template. Following the trials, between September 2012 and March 2014, this new open innovation evaluation framework was implemented in all pilots.

\section{Results and discussion}

This section contains an account of the SmartiP pilots' experiences in trialling the Co-evaluation Framework by using the Toolkit. It highlights their responses to the framework and templates offered to them for undertaking and reporting their selfassessments. Differences in how the pilots applied the contents of the Toolkit to the Framework are discussed along with the main benefits and barriers they encountered in trying to co-evaluate their co-production activities. 'Emerging' lessons about external stakeholders' participation in co-production and about the need to integrate "technological" and "social" innovation processes are also signalled along with related research and policy issues

\subsection{Engaging with the stakeholders}

All pilots attracted a great number of actors in their co-production activities.

Together, they trialled the SmartiP co-evaluation framework and reported back to the evaluation team the variety of techniques they used for engaging with the stakeholders in co-production - ranging from one-to-one discussions to focus groups, informal interviews and site visits, crowdsourcing (in Ghent through "My Digital Idea for Ghent Campaign" and in Manchester Tellus - by forming a household network to empower citizens to find solutions about renewable heat and home insulation), to cocreative workshops, and online surveys. Citizens' participation was sought for different purposes of co-production - for mapping out the new smart city service, collaborative service design, prototyping as well as for creating the content of the new services. They also reported the broad range of citizens engaged in co-production, from ordinary citizens (students, neighbourhood residents), experts from various 
fields (artists, creatives, academics, business people, technologists, activists, commercial representatives (manufactures, installers, retailers, consultants), to research communities, as well as SmartiP partners and their public sector colleagues.

All pilots reported trialling the templates from the Toolkit for co-evaluating their initial service development activities but did this with varying degree of understanding and with mixed levels of deployment. The results of their trialling were uneven in terms of both depth and completeness, especially in terms of the quality of their analyses and of their reporting against the Framework. Three of the pilots reported against almost all aspects of the co-evaluation framework, including carrying out a Peer Review Co-evaluation Exercise. The other two only gave brief accounts of their adoption of the framework and their future plans, addressing only basic questions such as "What did we do well?" and "What could we do better?".

Overwhelmingly, trial reports showed that making co-production an inclusive process was attempted by all partners except Manchester City due "to the highly specific nature of the technology and the sensibility of the vested interests by the various stakeholders concerned". Often citizens were engaged from the very early stage of co-conceptualisation and co-design of their service prototype, taking into account their needs and preferences. The more advanced pilots, such as Tellus, Ghent and Bologna, employed co-evaluation activities throughout the entire front end of coproduction.

\subsection{Applying co-evaluation}

Despite its "theoretical basis", as some practitioners described it, the coevaluation framework was generally well received by all city pilots once they tried to apply it. But many expressed substantial difficulties in conducting co-evaluation. As the pilots lacked previous experience in co-evaluation of public services, all indicated the need of further sharing the experience amongst them as well as early training for both project managers and pilot members. These two factors were signalled as decisive for effective implementation of service co-evaluation. Pilot teams' understanding of, and ability to apply, self-reflection in order to critically assess progress of their co-production activities was recognised as critical by all. More attention to, and training in, self-reflection right at the start of service development would have made their practice of co-evaluation smoother.

But despite the lack of preparedness, all pilots welcomed the new SmartiP approach to co-evaluation, regardless their difficulties in adopting it. Their reports showed a good evidence of the types of activities they undertook during the initial stages of co-production.

- $\quad$ engaging with stakeholders to co-create visions

- active dialogue and roundtable discussion for co-designing prototype

- $\quad$ prototype development using collaborative participation techniques, focused groups, and training sessions, and

- $\quad$ gathering views and experiences expressed by stakeholders on prototypes via user friendly tests and focus groups.

All pilots acknowledged, however that they saw no gaps in the co-valuation framework. Some signalled that such gaps might occur later, during the testing and use of the service prototypes in their cities. One partner suggested that the framework needed to be further enhanced in regard to "re-use" to respond better to sustainability and the transferability of not just technology, but of the new services as well. Although some partners struggled with it, some more than others, none of the pilots 
suggested other elements that needed to be added to the SmartiP Evaluation Framework.

\subsection{Defining service objectives and relevant benchmarks of success}

Pilots reported that setting up parameters for the new services with the citizens was, typically, a successful exercise. Using co-evaluation in the design phase proved highly beneficial, not just for the progress of the new Internet-enabled applications but for charting out other areas in which engaged partners could co-develop as well. For example, Manchester's Community Reporters created a new body called the Institute of Community Reporters which is being used to support local issues reporters across the UK and in the evolving European Network of Community Reporters.

One weak point of the trials was the limited reporting of framing and evaluating technology innovations. Despite accounts of various activities carried out to fine tune service prototypes, detailed analysis of how these experiments led to improvements in service development were missing from the pilot reports even though a template for this was provided to help report such activities and identify their outcomes. Likewise, defining indicators for measuring the social innovation aspects of their new services proved particular hard for the pilots. Attention to what was being done in each of the pilots to integrate their technological and social innovations was also absent from the trialling reports. Similarly, there was scant evidence of them making a real use of indicators and benchmarks in reporting progress of co-production. In practice, where this occurred, defining qualitative and quantitative indicators, along with mapping out the implications of services for policy, were mostly done by project partners without involving external stakeholders.

Most pilots only submitted general recording of the events they ran. Given the importance placed in the co-evaluation framework on assessing dialectically the coproduction process, the activities engaged in, and their outcomes, this absence was flagged up as a significant omission that needed to be remedied during the remainder of the project. In parallel, however, identifying the added value of the new services was reportedly underway in most pilots. Linking their impacts to policy and to real life benefits for the citizens had been tackled directly during the concept building phase.

\subsection{Analysing progress}

Some pilots employed a more comprehensive approach to co-evaluating the progress of their co-production activities: others were more ad hoc. Ghent, for example, used the proposed co-evaluation framework most thoroughly, following a cycle of action and reflection aimed at critically examining their on-going activities, learning by doing, and then incorporating this into their following day-to-day activities. They kept a record of these activities and of the feedback results from their prototype trials, and produced an evaluation report of their crowdsourcing. Their coevaluation underlined that the results from their focus groups had been especially important for them. They went on to co-evaluation through self-reflection. Their SCOGA/KLIEK co-creation process was also being monitored and evaluated by an external third party - an expert from the University of Twente. While Ghent brought its various stakeholders together in truly collaborative activities, Cologne opted instead to use a range of activities each targeted at an individual stakeholder group - 
local IT systems officials, communication managers, civil servants, students, and local citizens engaged in participatory budgeting. These were engaged through public forums, interviews, questionnaires, and methodological discussions with local politicians and visitors from Malmö. Cologne also worked with city departments to test ideas for their new platform; for example, with the planning department about noise reduction. This experience led them to acknowledge that working directly with politicians and strategy officers prior to and during the development of the new service platform would have made their co-production process smoother. They also made use of intensive public relations, especially through Facebook and Twitter, around implementing their QR codes.

Overall, pilots reported that trialling the co-evaluation framework helped them improve their understanding of the social innovation aspects of their new services. But the trialling reports showed that linking these with specific benchmarks of success proved difficult, especially for non-academic partners. Defining and measuring the overall success of their service demonstrators, against both the smart city overall objectives and local citizen and policy demands, were also revealed as challenging.

\subsection{Difficulties uncovered}

Four key lessons emerged from the trialling of the co-evaluation framework against the Toolkit templates about difficulties the pilots experienced undertaking the following tasks:

1. applying co-evaluation to activities conducted in their LL pilots

2. framing pilots' service objectives against the SmartiP smart city agenda as well as their city's specific policies

3. identifying relevant benchmarks of success, including measurable indicators, throughout the full lifecycle of co-production

4. purposefully analysing pilots' progress in co-production to provide formative (and perspective summative) assessments of the success of their new services and their potential impacts.

On the positive side, pilots' reports indicated that, during the front end stages of the project, they were also developing the capabilities required to undertake these four tasks. Yet pilots did so to very variable degrees. Those that had research partners as pilot members appeared better placed than those with only city or NGO partners. In all six pilots, preparing for and then conducting trialling activities was reportedly straightforward. But capturing and reporting the outcomes of pilots' co-production activities through co-evaluation revealed significant weaknesses.

\subsection{Management skills for overcoming shortfalls}

Trials of the Co-evaluation Framework highlighted three important skills that public sector managers needed to exercise:

1. an ability to enhance the social capital of both internal and external stakeholders - in terms of their capacity to contribute to co-production - by engaging them effectively in activities required throughout the whole process to support the emergence of new civic services

2. a parallel ability to enhance the social capital of both internal and external stakeholders - in terms of their capacity to practice co-evaluation - in order 
to collaboratively evaluate the progress being made, at each stage in the coproduction process, of their emergent civic services

3. an overarching ability to bring both of these skills together, at each stage in the co-production process, in order to ensure that the development of both types of social capital is matched and mapped on to parallel technological developments, so resulting in a more fully integrated approach to sociotechnological innovation.

Pilots' reports showed that public sector managers responsible for the smart city services did not exercise all three of the skills described above equally. Some were able to enhance their stakeholders' capacity to contribute to the activities needed to support co-production. Fewer were able to enhance their stakeholders' capacity to engage in reflective co-evaluation. And the overarching ability to integrate the social and technological strands of innovation practice was rarely evident from how the public sector managers reported their trialling of the Evaluation Framework and Toolkit.

All of the skills listed above appear to be necessary to make co-evaluation and the open innovation approach underpinning co-production in LLs capable of delivering the benefits claimed for it in the literature. If smart cities are to achieve what is being promised, then much more time and effort will need to be invested - at the front end of the projects aimed at citizen-centred, internet-enabled civic services in providing explicit underpinnings for, and upgrading of, public sector managers' missing or under-developed skill sets in stakeholder engagement, in self-reflective and collaborative evaluation, and in the integration of social and technological developments in public sector service management.

\section{Conclusions}

Although there is growing attention to co-production of smart city services, debate is still lacking about (comprehensive and competent) evaluation of their successful delivery. Conventional performance measurement for local government services provides an inadequate basis for realising the full potential of the role of evaluation in co-production. Understanding evaluation of smart city services, as this paper reveals, requires an open innovation approach that appreciates both the effectiveness of the stakeholder collaboration as well as its efficacy in terms of the outcomes - the new public services - and their impacts on the wellbeing of the citizens and the city.

The present study offers a stepping-stone towards advancing open innovation to evaluation of civic services by proposing a new, procedurally- focused, conceptual model grounded in practical experience. Theory and practice-based approaches to coproduction and public service evaluation are used to offer a co-evaluation methodology which public service providers experimenting with co-production can use to assess its success. The adopted co-evaluation framework addresses a puzzle neither theoreticians nor public sector practitioners test smart city co-production claims before proclaiming them. Co-evaluation anticipates the engagement of all key stakeholders in co-production as active co-producers in a systematic and continuous co-evaluation process based on self-assessment of the success of the services being produced. This requires that the processes employed, and the activities involved, have to be tailored to the specific context of the city or district which hosts them and are made explicitly relevant and usable to the partners involved and their needs. Unlike the predominant performance measuring approaches of government management of 
services, the new co-evaluation approach focuses on measuring four key components of developing the new services being pursued by a smart city - processes, activities, outcomes and impacts (see also Duignan, 2009). It also provides for the indicators that cities may consider in evaluating their service effectiveness, reflective of all partners' intentions. The present work offers a new perspective on what kind of value is being created in the smart city service, one that is wished for and apparent to the co-producers. With this co-evaluation approach, dependency is recognised between the key main factors involved in co-production - actors, the actions, the product, and its impacts on the city and its people. Values (in the form of stakeholders' expressed aspirations) at the service project's onset can be compared to those perceived as having been realised at its completion. This emphasises the importance of engaging stakeholders in establishing the baselines against which their perceptions of success can be assessed.

The paper has drawn on the public service innovation and Living Lab literatures to identify dynamics that may lead to more effective adoption of co-production and co-evaluation in smart city service practices. The analysis suggests that co-production can be successful providing stakeholders are engaged through the entire life cycle of the services co-production in "real time" "self-assessment" activities. It is stressed that co-production and co-evaluation have to be understood as parallel, iterative and interactive processes involving both internal and external stakeholders. The findings indicate that co-evaluation not only needs to address technology innovation but to integrate this with social innovation as well. This, in turn, requires effective stakeholder engagement along with the organisational and management capabilities necessary for adapting this to specific smart city circumstances. The study has highlighted that co-evaluation is a critical component of innovation management of smart city services and has drawn attention to the specific arrangements that service managers need to make in order to robustly engage with the citizens as co-producers. The main skills sets needed for effective co-evaluation of open innovation services are the integration of stakeholder management with evaluation capacities.

With internet technologies becoming more ppervasive, the gap between internetenabled services and government ability to effectively manage public service in the smart city is likely to increase unless local governments prepare to manage coproduction processes more effectively in their cities. This paper has found that in the cases explored, there was a growing need for service mangers and city governments to build this capacity. Well-developed managerial capabilities in co-evaluation will be essential to delivering this.

\section{Acknowledgement}

Special thanks go from the authors to all the partners and their stakeholders involved in SmartiP. We particularly thank Jenni Vitaanen and Peter Mechant for their contributions to the SmartiP Validation strategy.

\section{Funding}

This work was partially supported by the European Commission, DG/RTD Information Society Technology, CIP-ICT-PSP-2010-4 [Grant No. 270971, 2010]. 


\section{Appendix A. Toolkit for capture and report of Pilot validation of SmartiP Co- Evaluation framework (concise version)}

Table 1. Peer review validation of co-evaluation

This simple process is proposed to collect feedback from each pilot on their validation of the SmartiP co-evaluation framework. Please report on the following queries:

1. Do pilot's objectives reflect the SmartiP project objectives?

2. Do the selected indicators/measures of success reflect adequately and/or usefully the objectives of the new service?

3. Who are the co-producers of the new service?

4. Are all concerned stakeholders involved?

5. What is the process of co-production (face to face or/and online)?

6. Is the proposed self-assessment methods appropriate; could other methods be considered?

7. Are there gaps in the SmartiP co-evaluation framework?

Table 2. Template for reporting self-assessment

Use this template to develop and report pilot self-assessment for validating Coevaluation.

1. Define how is 'co-production' incorporated into service development?

2. Establish the mechanisms for applying co-evaluation in pilot (key steps, actions, results, outcomes)

3. Identify level of achievement of pilot objectives set out at beginning of service development;

4. Identify 'roadblocks ' to co-evaluation and ways to overcome them;

5. Highlight key service innovations (social and/or technological) in their integration;

6. Map out main benefits from co-production and co-evaluation;

7. Finalise key benchmarks of service success for implementing co-evaluation during whole lifecycle of co-production.

8. Define the final strategy and methods.

9. Map out pathways and opportunities for co-use and re-use of service in your city and with other SmartiP cities.

\section{References}

Albury, D. 2005. Fostering Innovation in Public Services. Public Money \& Management 25 (1): 51-56.

Almirall, E., Wareham, J. 2008. Living Labs and open innovation: roles and applicability. The Electronic Journal for Virtual Organizations and Networks, 10 (3): 21-46.

Al-Yaseen, H., Eldabi, R., El-Haddadeh, R. 2008. Post Implementation evaluation of IT systems: a close review of practice, in: Irani, Z., Lowe, P. (Eds), 
Evaluating Information Systems: Public and Private Sectors, ButterworthHeinemann, Oxford, UK, pp. 134-151.

Axelsson, K., Melin, U., Lindgren, I. (2010): Exploring the Importance of Citizen Participation and Involvement in e-government Projects: practice, incentives and organization, Journal of Transforming Government - People, Process and Policy, 4(4): 299-321.

Bommert, B. 2010. Collaborative innovation in the public sector. International Public Management Review, 11(1):15-33.

Borins, S. 2001. Encouraging innovation in the public sector. Journal of Intellectual Capital, 2 (3): 310-319.

Bouckaert, G., Van de Walle, S. 2003. Comparing measures of citizen trust and user satisfaction as indicators of 'good governance': Difficulties in linking trust and satisfaction indicators. International Review of Administrative Sciences 69(3): 329-344.

Bovaird, D., 2007. Beyond Engagement and Participation: User and Community Coproduction of Public Services. Public Administration Review 67(5):846860.

Bovaird, T., Loeffler. E. 2012. From Engagement to Co-production: The Contribution of Users and Communities to Outcomes and Public Value. International Journal of Voluntary and Nonprofit Organizations 23 (4):11191138.

Boyle, D., Harris, M. 2009. The Challenge of Co-production: how equal partnerships between professionals and the public are crucial to improving public services. New Economic Foundation, NESTA. London.

Cahn, E., Ch. Gray. 2013. Co-Production from a Normative Perspective. New Public Governance, the Third Sector, and Co-Production 7:129.

Chen, J., Tsou, H. Ching, R. 2011. Co-production and its effects on service innovation. Industrial Marketing Management 40 (8): 1331-1346.

Chesbrough, H. 2011. Open Services Innovation: Rethinking Your Business to Grow and Compete in a New Era, Wiley, New York.

Cooper, I., Paskaleva, K., Concilio, G., Rizzo, F., Goetz, C., Marsh, J., Barroco, J. 2012. Smart City Services Evaluation and Impact Assessment Report D6.2.1, Peripheria Project, http://www.peripheria.eu/content/peripheria-evaluation-andimpact-assessment

Damanpour, F., Schneider, M. 2009. Characteristics of Innovation and Innovation Adoption in Public Organizations: Assessing the Role of Managers. Journal of Public Administration Research and Theory 19(3), 495-522.

Dollery, B., Grant, B., Akimov, A. 2010. A Typology of Shared Service Provision in Australian Local Government. Australian Geographer, 41(2): 217-231.

Duignan, P. 2009. Selecting impact/outcome evaluation designs: a decision-making table and checklist approach, in: Outcomes Theory Knowledge Base, article no. 256. http://knol.google.com/k/paul-duignan-phd/selectingimpactoutcomeevaluation/2m7zd68aaz774/115).

Durose, C., Mangan, C., Needham. C., Rees, J. 2014. Evaluating co-production: pragmatic approaches to building the evidence base, Co-production Panel, Political Studies Association Conference, April.

ENoLL n.d. What is a Living Lab. http://www.openlivinglabs.eu/node/1429

Flak, L., Jeremy, R. 2005. Stakeholder Governance: Adapting Stakeholder Theory to E-Government, Communications of the Association for Information Systems 16 , Article 31. 
Frederickson, H., Smith, K. 2012. Public Administration Theory and Primer. Boulder, Co: Westview Press.

Grimsley, M., Meehan, A. 2007. e-Government information systems: Evaluation-Led Design for Public Value and Client Trust, European Journal of Information Systems 16(2):134-148.

Gummesson, E. 1994. Service Management: An Evaluation and the Future. International Journal of Service Industry Management 5 (1): 77 - 96.

Hilgers, D., Ihl, C. 2010. Citizen sourcing: Applying the Concept of Open Innovation to the Public Sector. The International Journal of Public Participation, 4(1): 6788 .

Holgersson, J., Karlsson, F. 2104. Public e-service development: Understanding citizens' conditions for participation. Government Information Quarterly 31(3): $396-410$

Huizingh, E. 2011. Open innovation: State of the art and future perspectives. Technovation 3(10): 2-9.

Irani, Z., Love, P.E.D., Jones, S. 2008. Learning lessons from evaluating eGovernment: Reflective case experiences that support transformational government. The Journal of Strategic Information Systems 17(2): 155-164.

Jager, B. 2013. User-involvement in public services innovation. In Handbook of Public Service Innovation, Osborn, S., Brown, L. (Eds.), Cheltenham: Edward Elgar.

JISC 2009. Facilitating open innovation: lansdcpaes and feasibility study. PERA The innovation network. http://www.jisc.ac.uk/media/ documents/programmes/bce/facilitatingopeninnovationstudyfinalreport.pdf

Joel, W. Salter, A., Vanhaverbeke, W., Chesbrough, H. 2014. Open innovation: The next decade? Research Policy, 43 (5): 805-811

Jones, S., Hackney, R., \& Irani, Z. 2007. Towards e-government transformation: Conceptualising "citizen engagement. Transforming Government: People, Process and Policy, 1(2): 145-152.

Jun, K., Weare, Ch. 2010. Institutional Motivations in the Adoption of Innovations: The Case of E-Government. Journal of Public Administration Research, and Theory 21 (3): 495-519.

Kettl, D. 2005. The global public management revolution, Washington, D.C.: Brookings Institution Press.

Komninos, N. 2009. Intelligent cities: towards interactive and global innovation environments. International Journal of Innovation and Regional Development $1(4), 337-335$.

Kuk G, Janssen M. 2011. The business models and information architectures of smart cities. Journal of Urban Technology 18(2): 39-52.

Lee, J., Lee, H. 2014. Developing and validating a citizen-centric typology for smart city services, Government Information Quarterly 31: S93-S105, p.S94.

Lin, F-R., Hsieh, P-Sh. 2010. Analyzing the sustainability of a newly developed service: An activity theory perspective. Technovation 34(2): 113-125.

Linders, D. 2012. From e-government to we-government: Defining a typology for citizen coproduction in the age of social media. Government Information Quarterly, 29(4): 446-454.

Löffler, E., Parrado, S. Bovaird, T. 2008 Ryzin van G. 2008. Citizens and the coproduction of public services. White paper commissioned by Ministry of Budget, Public Finance and Public Services, France. 
Meijer, A. 2012. Networked co-production of public services in virtual communities: From a government-centric to a community approach to public service support. Public Administration Review, 71(4): 598-607.

Mulder, I., Stappers, P.J. 2009. Co-creating in Practice: Results and Challenges, in: ICE International Conference on Concurrent Enterprises, 22-24 June, Leiden, The Netherlands.

Mulgan, G., Albur, D. 2003. Innovation in the public sector. Strategy Unit, Cabinet Office, UK.

Nonaka, I., Takeuchi, H. 1995. The Knowledge Creating Company: How Japanese Companies Create the Dynamics of Innovation. Oxford University Press, Oxford, UK.

OECD 2011. Together for Better Public Services: Partnering with Citizens and Civil Society, OECD: Paris.

OECD 2012. Innovation in the Public Services: Context, Solutions and Challenges, OECD: Paris.

Osborne, S., Brown, L. 2013. Introduction: innovation in public services, in Osborne, S., Brown, L. (Eds.) Handbook of Innovation in Public Services, Edward Elgar.

Osborne S., Radnor, Z.,Vidal, I., Kinder, T. 2014. A Sustainable Business Model for Public Service Organizations? Public Management Review, 6(2):165-172.

Paskaleva, K. 2011. The smart city: A nexus for open innovation? Intelligent Buildings International Journal 3:153-171.

Paskaleva, K., Vitaanen, J., Mechant, P. 2012. Smart Citizens in Smart Cities: An Evaluation Strategy and Method, SmartiP Project report D7.1. http://www.smart-ip.eu/SmartiP EU Project Report.

Paskaleva. K., Cooper, I., Linde, P., Peterson, B, Götz, Ch. 2014. Smart City Stakeholder Engagement: Making Living Labs Work, in: Bolívar, M. (Ed.), Transforming City Governments for Successful Smart Cities, Springer.

Patton, M. 2005 Toward Distinguishing Empowerment Evaluation and Placing It In A Larger Context, American Journal of Evaluation 18 (1):147-163.

Percy, S. L. (1984). Citizen participation in the coproduction of urban services. Urban Affairs Quarterly 19:431-436.

Percy, S. L. (1986). In defence of citizen evaluations as performance measures. Urban Affairs Quarterly, 22: 66-83.

Pestoff, V. 2012. Co-production and third sector social services in Europe-Some crucial conceptual Issues, in: Pestoff, T., Verschuere, B. (Eds.), New public governance, the third sector and co-production. London: Routledge.

Pollitt, Ch., Geert, B., Löffler, E. 2006. Making quality sustainable: co-design, codecide, co-produce, co-evaluate, Report of the 4QC Conference, Tempere, 1-22.

Rondinelli, D. 2013. Reinventing government: the imperatives of innovation and qualaity: http://unpan1.un.org/intradoc/groups/public/documents/un/unpan010867.pdf

Sanderson, I. 1996. Evaluation, learning and the effectiveness of public services', International Journal of Public Sector Management, 9(5/6), pp. 90108.

Santos, A. 2015. Open Innovation research: trends and influences - a bibliometric analysis. Journal of Innovation Management 3(2):131-165.

Sicilia, M, Guarini, E., Sancino, A., Andreani, M., Ruffini, R. 2016. Public services Management and co-production in multi-level governance settings. International Review of Administrative Sciences, 82(1):8-27. 
SmartiP (n.d.). SmartiP: Smart citizens in smart cities. http://www.smart-ip.eu Sørensen, E., Torfing, J. 2012. Introduction: Collaborative Innovation in the Public Sector. The Public Sector Innovation Journal 17(1).

Ståhlbröst, A., Bergvall-Kåreborn, B. 2008. FormIT - an approach to user involvement, in: Schumacher, L., Niitamo. J., (Eds.) European Living Labs - A new approach for human centric regional innovation, Wissenschaftlicher Verlag: Berlin.

Ståhlbröst, A., Holst, M. 2012. The Living Lab Methodology Handbook. Plan Sju kommunikation AB, Sweden.

Strokosch, K. 2013. Co-production and Innovation in Public Services: Can Coproduction Drive Innovation? in: Osborne, S., Brown, L. (Eds) Handbook of Innovation in Public services, Edgar Elgar.

Van den Ryzin, G., Immerwahr, S. 2007. Importance-performance analysis of citizen satisfaction surveys. Public Administration, 85(1):215-226.

Vargo, S., Maglio, P., Akaka, M. 2008. On value and value co-creation: A service systems and service logic perspective. European Management Journal 26:145152. 